\title{
Control of Lead Workers by Determination of Urinary $\delta$-Aminolaevulinic Acid
}

\author{
KIM CRAMÉR and STIG SELANDER \\ From Medical Service I and the Department of Hygiene, University of Göteborg, Göteborg, \\ and from $A B$ Tudor, Nol, Sweden
}

The output of $\delta$-aminolaevulinic acid (ALA) and of creatinine was determined in lead workers. Values from 24-hour specimens were compared with values from specimens voided at the time of examination. Highly significant positive correlations were found between the output of ALA and of creatinine in both sets of specimens. The individual spreads, however, were considerable.

Values for ALA in mg./100 ml. urine and ALA in mg./g. creatinine were strongly correlated in fresh specimens as well as in 24-hour specimens. When values for ALA in mg./100 ml. urine were compared with ALA in $\mathrm{mg} . / \mathrm{g}$. creatinine, an approximate relationship of $\mathrm{I}: 5$ was found in the range $1.0-3.0 \mathrm{mg}$. ALA/100 ml. urine, i.e., the mean urinary concentration of creatinine was $0.2 \mathrm{~g} . / 100 \mathrm{ml}$.

It is concluded that the collection of 24 -hour specimens is not necessary and also that reference to creatinine appears to have no advantage over the simple expression of ALA in mg./100 ml. urine. This must be due to the fact that the influence of the metabolic activities of lead has a greater effect on the urinary concentration of ALA than has the concentration of urine in the kidneys.

The determination of $\delta$-aminolaevulinic acid (ALA) in urine has been shown to be a sensitive indicator of lead-poisoning (Haeger-Aronsen, 1960; Cramér and Selander, 1965). It has been found that the urinary output of ALA, in a lead-exposed worker, is closely related to the amount of lead that can be excreted from the body during therapy (Cramér and Selander, 1965).

In the regular control of factory workers, several practical problems arise. Two are examined here: Should determinations of the output of urinary solutes be carried out on specimens voided at the time of examination, or should they always be performed on 24-hour urine specimens? Is it necessary to relate the urinary output of the solute to the output of creatinine or to the specific gravity of urine?

In a previous paper (Cramér, Cramér, and Selander, 1967) we showed that the daily variations in the urinary output of creatinine are of the same magnitude as the variations in urinary volume. Provided that the subject is kept on a varied diet with different intakes of creatine from day to day, no greater accuracy is obtained by relating the output of a solute to the output of creatinine. All the

Received for publication March 15, 1967. patients in that series, however, were observed during treatment for lead intoxication and were in-patients in hospital. The present study was performed to ascertain whether these findings are also valid for persons at work and if any trend could be observed which makes it necessary to determine urinary creatinine as well as the solute in question. It was also of importance to know whether samples freshly voided at the time of examination give the same information as 24 -hour specimens of urine.

\section{Material and Methods}

The study was carried out at the Tudor Storage Battery Works in Nol, Sweden. The regular control of lead workers was begun in I94I and included the collection of 24-hour specimens for determination of urinary coproporphyrins as well as of freshly voided specimens of urine for examination of urinary sediment.

All the workers were well acquainted with this system, and it was emphasized that the routine should be followed rigidly throughout the period of study. For obvious reasons it was impossible to control the individual worker at home, and this may render the comparison between 24-hour specimens and fresh specimens somewhat inaccurate. The general impression, however, was that cooperation was excellent, and that the error introduced by their disregarding the instructions could 
be ignored. The 24-hour volume was not recorded.

The study was performed in 1964 when coproporphyrins were still being determined. This test was later replaced by ALA determinations. Estimations of ALA were performed by the method of Mauzerall and Granick (1956) and those of creatinine in a Technicon Auto-Analyzer by the method of Jaffe (I886).

The factory workers start work at 6 a.m. and the examinations took place between 9.30 and II.30 a.m. All workers who came for regular examination during a three-week period were included in the study. Analyses of ALA as well as of creatinine were performed on 58 pairs of samples from 24-hour specimens as well as from fresh specimens. In all, ALA and creatinine were determined in 67 24-hour specimens and in 86 fresh specimens.

\section{Results}

The mean values, standard deviations, and coefficients of variation for urinary creatinine, $\mathrm{ALA}$, and $\mathrm{mg}$. ALA/g. creatinine are given in Table I for 24-hour specimens and for fresh specimens.

The original distribution of ALA concentrations and of mg. ALA/g. creatinine were skew, and calculations were performed after logarithmical transformation, which reduced the skewness. The values given in Table I have been transformed to concentrations or $\mathrm{mg} . / \mathrm{g}$. creatinine, but the coefficients of variation refer to the logarithmically transformed values. In each pair of observations, 24-hour and fresh, there was no significant difference between the mean values, and the coefficients of variation were also of the same order in each pair. The individual values are given in Table II.

The urinary concentration of ALA and the concentration of creatinine are shown for 24-hour specimens in Fig. I and for fresh specimens in Figure 2. In both cases there was a strong positive correlation between the values, although the individual spread was considerable. Judging from these figures, a correction for the renal concentration of urine, expressed as the concentration of creatinine, seemed to be justified.

Figure 3 shows the ALA output, expressed in mg./g. creatinine, in fresh and 24-hour specimens. The correlation was very strong $(n=58, r=0.94$, $P<0.00 I)$ and the individual spread almost negligible. The same comparison between fresh specimens and 24-hour specimens is shown in Fig. 4 for ALA expressed in $\mathrm{mg}$./100 ml. urine. The picture was almost the same as that in Figure 3 $(\mathrm{n}=58, \mathrm{r}=0.91, \mathrm{P}<0.001$ ).

Figure 5 shows ALA expressed in $\mathrm{mg}$./100 $\mathrm{ml}$. urine plotted against ALA related to the output of creatinine in 24-hour specimens. Figure 6 shows the same plot for fresh specimens. In both cases a strong correlation was obtained with the following regression equations:

24-hour specimens:

ALA mg./100 ml. = $0.20 \times($ ALA mg./g. creatinine $)-0.04$

Fresh specimens:

$$
\begin{gathered}
\text { ALA mg. } / 100 \mathrm{ml} .= \\
0.25 \times(\text { ALA mg./g. creatinine })-0.21
\end{gathered}
$$

These plots will in effect test the constancy of creatinine output at different levels of ALA output, and the equations will give a numerical expression of this value. In the region $0.6-3.5 \mathrm{mg}$. ALA/100 ml. urine it was found that the concentration of ALA numerically was roughly one-fifth of the figure for $\mathrm{mg}$. ALA/g. creatinine, which in turn means that the mean concentration of creatinine was about $200 \mathrm{mg}$. $/ 100 \mathrm{ml}$. This was valid for both sets of specimens and corresponds to the overall mean concentration of $172 \mathrm{mg}$. creatinine/100 $\mathrm{ml}$. found in 24-hour specimens, and $196 \mathrm{mg}$. creatinine/100 $\mathrm{ml}$. found in fresh specimens.

TABLE I

Mran Values, Standard Deviations, and Cogfricients of Variation for Creatinine Concentration, Ala

\begin{tabular}{|c|c|c|c|c|c|c|c|}
\hline & & \multicolumn{2}{|c|}{$\begin{array}{l}\text { Creatinine Concentra- } \\
\text { tion (mg./100 ml. urine) }\end{array}$} & \multicolumn{2}{|c|}{$\begin{array}{l}\text { ALA Concentration } \\
(m g . / 100 \text { ml. urine })\end{array}$} & \multicolumn{2}{|c|}{ mg. $A L A / g$. creatinine } \\
\hline & & 24 hours & Fresh & 24 hours & Fresh & 24 hours & Fresh \\
\hline $\begin{array}{l}\text { Mean } \ddot{3} \quad \ldots \\
\text { Standard deviation or standard deviation range } \\
\text { Coefficient of variation } \ldots\end{array}$ & $\begin{array}{l}\ldots \\
\cdots \\
\ldots\end{array}$ & $\begin{array}{l}172 \\
61 \\
0.36\end{array}$ & $\begin{array}{r}196 \\
64 \\
0.33\end{array}$ & $\begin{array}{l}0.51 \\
0.24-1 \cdot 10 \\
0.47^{1}\end{array}$ & $\begin{array}{c}0.63 \\
0.28-1 \cdot 30 \\
0.44^{1}\end{array}$ & $\begin{array}{l}3 \cdot 2 \\
1 \cdot 7-6 \cdot 3 \\
0 \cdot 57^{1}\end{array}$ & $\begin{array}{c}3 \cdot 4 \\
1 \cdot 7-6 \cdot 8 \\
0.57^{1}\end{array}$ \\
\hline
\end{tabular}
Concentration and mg. ALA/G. Creatinine in 24-hour SPecimens and in Freshly Voided SPecimens

${ }^{1}$ For the logarithmically transformed values.

The table contains values from the 58 pairs of collections in which complete sets of determinations were obtained. Computation of values for ALA concentrations and $\mathrm{mg}$. ALA/g. creatinine were performed on logarithmically transformed figures to reduce the original skew distribution. 


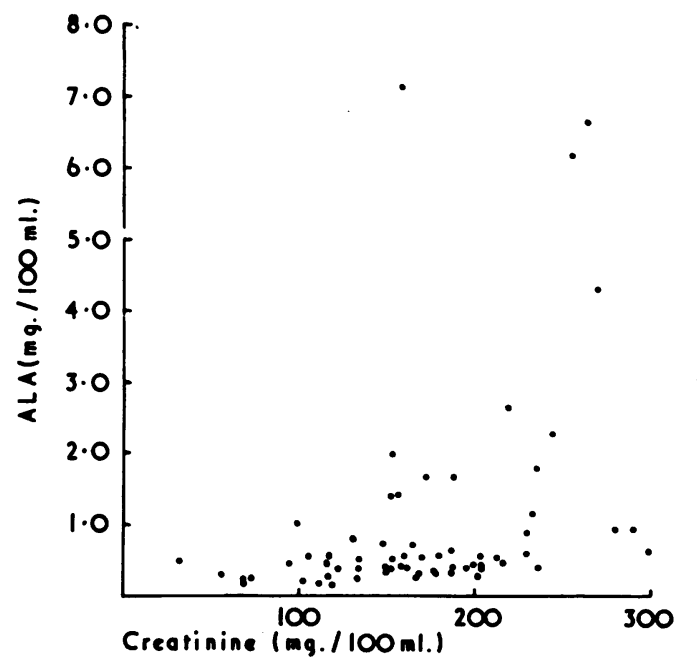

FIG. I. Concentrations of creatinine and of ALA in 24-hour specimens from 67 lead workers: $r=0.39, P<0.001$.

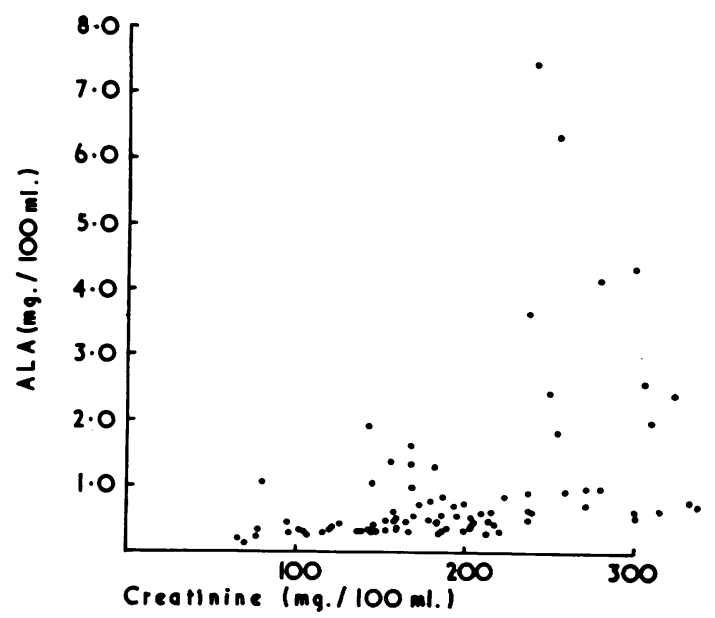

Fig. 2. Concentrations of creatinine and of ALA in freshly voided specimens from 86 lead workers:

$\mathbf{r}=0.42, \mathbf{P}<0.001$.

\section{Discussion}

The concept of a more or less constant urinary output of creatinine, referable to the body muscle mass, has previously been questioned by several authors (Doolan, Alpen, and Theil, 1962; Bleiler and Schedl, 1962; Paget, Liefooghe, Duhamel, and Parent, 1962). In general, variations in creatinine output reflect variations in creatine intake (Bleiler and Schedl, 1962) and the renal concentration of urine. Variations in the output of ALA, on the other hand, depend on the metabolic influence of lead (Haeger-Aronsen, 1960) as well as on the renal

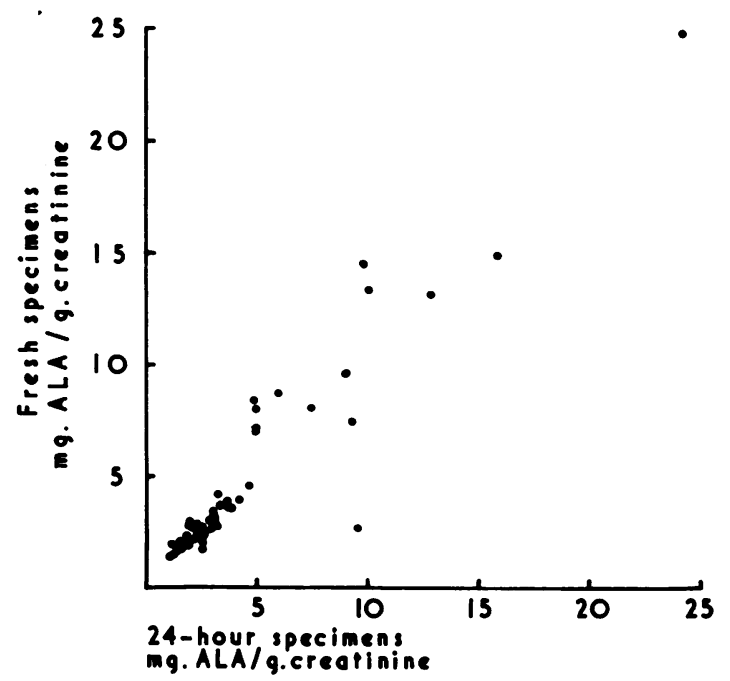

FIG. 3. ALA, expressed as mg./g. creatinine in urine from 58 lead workers, values from 24 -hour specimens and from freshly voided specimens: $r=0.94, P<0.001$.

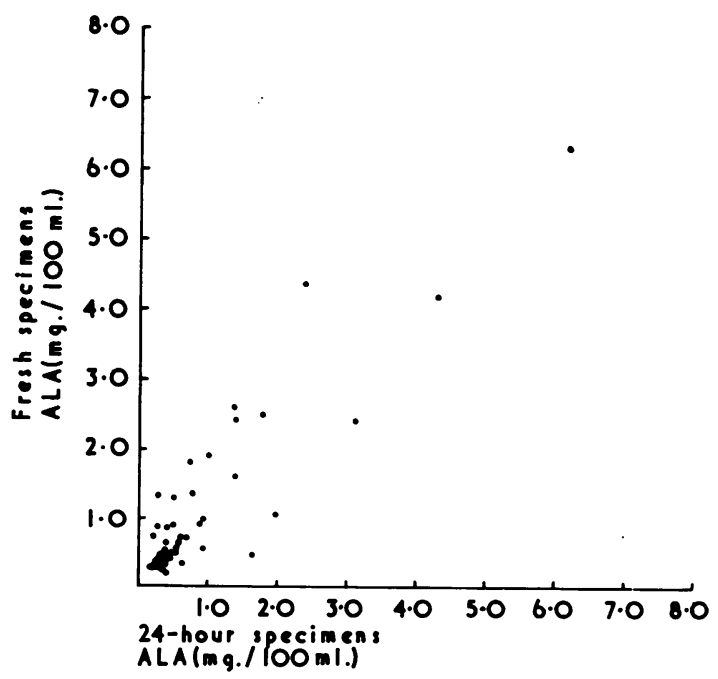

Fig. 4. ALA, expressed as $\mathrm{mg}$./100 $\mathrm{ml}$. urine, in urine from 58 lead workers, as in Fig. 3. Values from 24-hour specimens and from freshly voided specimens:

$r=0.91, P<0.001$. 


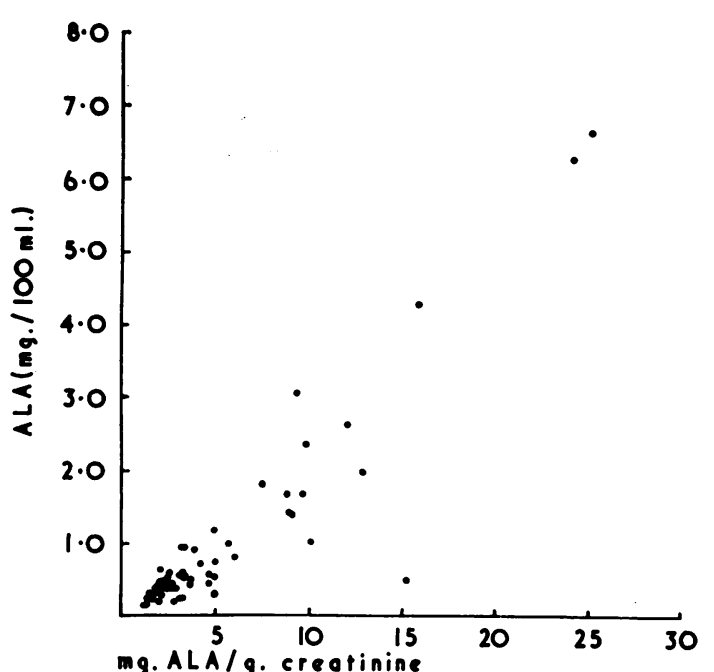

Fig. 5. ALA, expressed as mg./g. creatinine, and as mg./100 ml. urine in 24-hour specimens from 58 lead workers. Regression equation:

AAL mg. $/ 100 \mathrm{ml} .=0.20 \times($ ALA mg./g. creatinine $)-$ 0.04 .

concentration of urine. If similar results are found when comparing ALA expressed as $\mathrm{mg}$./100 $\mathrm{ml}$. urine and ALA in relation to creatinine output, this must mean that the metabolic activities of lead have a greater influence on the ALA concentration in the urine than the concentration of urine in the kidneys.

Our own studies on hospital in-patients with a varying dietary intake of creatine daily (Cramér et al., 1967) indicate that the relation of the output of a solute to the output of creatinine is of no greater value than the expression of the solute in units of urinary concentration. In routine control work, all persons examined will have different intakes of creatine, and they are therefore more comparable with hospital patients, like those in our previous study, than with persons investigated in metabolic wards on a formula diet or on very standardized ordinary food.

In agreement with our earlier observations, the present study shows the expression of ALA output in $\mathrm{mg} . / 100 \mathrm{ml}$. urine to be equally as valuable as the expression of ALA output in mg./g. creatinine.

It is of considerable interest to know whether it is necessary to collect 24-hour specimens or whether the information from freshly voided specimens is of equal value. This question has previously been studied by Buchwald (1964), who found a correction for the specific gravity of urine to be highly effective in eliminating the influence of urinary dilution in

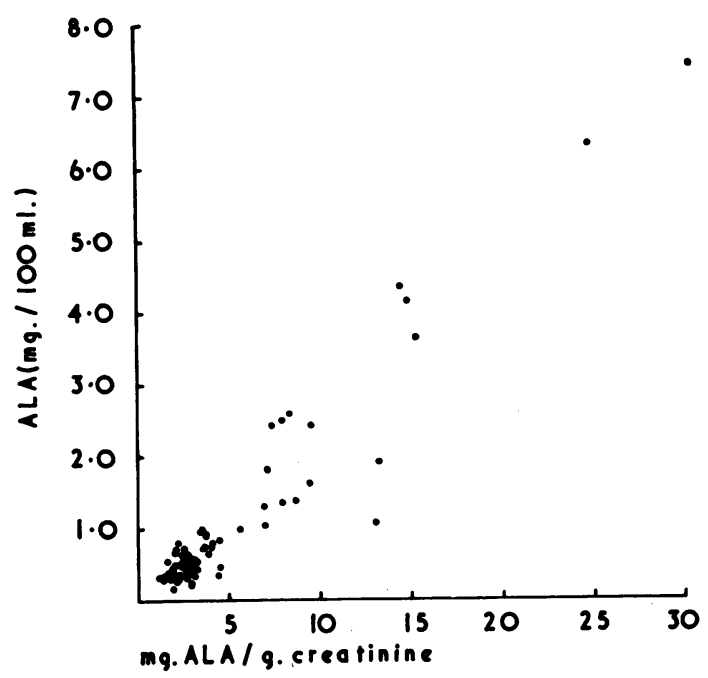

FIG. 6. ALA, expressed as in Fig. 5 in freshly voided specimens from the same 58 lead workers:

Regression equation:

ALA mg. $/ 100 \mathrm{ml} .=0.25 \times($ ALA mg./g. creatinine $)-$ 0.21 .

the daytime, and proposed a specific gravity of I.0I6 as applicable to the British Isles (Buchwald, I965). Molyneux (I964) compared values for lead in urine corrected for urinary specific gravity and for creatinine output. The corrected values were found to be in the same range, but they showed no particular advantage compared with the expression of lead in urinary concentrations. Ellis (1966) has recently compared lead and coproporphyrin outputs in relation to creatinine and to specific gravity. In addition, he introduced the concept of a 'mean concentration' derived from pooled data on urinary volume and output of the solute in question. By means of a statistical method for comparing the coefficients of variation, he found higher coefficients of variation after the corrections than before, i.e., the corrections had no practical value and were rather misleading.

These findings differ from those of Buchwald (1964) but agree to a certain extent with ours (Cramér et al., 1967) which use a proposed statistical method for the comparison of coefficients of variation, which is more powerful and more satisfactory. It is nevertheless somewhat unexpected to find, as in the present study, that values from freshly voided specimens agree well with those from 24-hour specimens. There are some possible explanations for this: 
TABLE II

Values for Urinary Creatinine Concentration, ala Concentration, and mg. ALA/g. Creatinine in 58 WORKERS WITH LEAD EXPOSURE

\begin{tabular}{|c|c|c|c|c|c|c|}
\hline \multirow{2}{*}{$\begin{array}{c}\text { Worker } \\
\text { No. }\end{array}$} & \multicolumn{2}{|c|}{$\begin{array}{c}\text { Creatinine } \\
\text { (mg./roo ml.) }\end{array}$} & \multicolumn{2}{|c|}{$\begin{array}{c}A L A \\
(\mathrm{mg} . / 100 \mathrm{ml} .)\end{array}$} & \multicolumn{2}{|c|}{$\begin{array}{c}A L A \text { (mg./g. } \\
\text { creatinine) }\end{array}$} \\
\hline & 24 hou & Fresh & 24 hour & Fresh & 24 hou & Fresh \\
\hline I & 230 & 238 & 0.60 & 0.63 & $2 \cdot 6$ & $2 \cdot 6$ \\
\hline 2 & 99 & 143 & $1 \cdot \infty$ & $1 \cdot 90$ & IO.I & 13.3 \\
\hline 3 & 148 & 255 & 0.74 & $1 \cdot 80$ & 5.0 & $7 \cdot 1$ \\
\hline 4 & 134 & 238 & 0.50 & 0.90 & $3 \cdot 7$ & 3.8 \\
\hline 5 & 134 & 105 & 0.36 & 0.28 & $2 \cdot 7$ & $2 \cdot 7$ \\
\hline 6 & 122 & 153 & 0.36 & 0.46 & $3 \cdot 0$ & 3.0 \\
\hline 7 & 68 & 272 & 0.21 & 0.71 & $3 \cdot 1$ & $2 \cdot 6$ \\
\hline 8 & 73 & 102 & 0.24 & 0.32 & $3 \cdot 3$ & $3 \cdot 1$ \\
\hline 9 & 68 & II 6 & 0.19 & 0.27 & 2.8 & $2 \cdot 3$ \\
\hline ro & 162 & I79 & 0.37 & 0.49 & $2 \cdot 3$ & $2 \cdot 7$ \\
\hline II & 167 & 221 & 0.24 & $0.3 I$ & $\mathrm{I} \cdot 4$ & $\mathrm{I} \cdot 4$ \\
\hline 12 & 153 & 187 & 0.50 & 0.56 & $3 \cdot 3$ & 3.0 \\
\hline 13 & 204 & 187 & 0.37 & 0.32 & $1 \cdot 8$ & I. 7 \\
\hline 14 & 187 & 204 & 0.30 & 0.40 & $1 \cdot 6$ & $2 \cdot 0$ \\
\hline 15 & 204 & 218 & $0.4 \mathrm{I}$ & 0.43 & $2 \cdot 0$ & $2 \cdot 0$ \\
\hline 16 & II 6 & 187 & 0.43 & 0.84 & $3 \cdot 7$ & 4.5 \\
\hline 17 & 213 & 184 & 0.53 & 0.46 & 2.5 & $2 \cdot 5$ \\
\hline 18 & 102 & 136 & 0.20 & 0.30 & 2.0 & $2 \cdot 2$ \\
\hline 19 & 119 & 213 & 0.14 & 0.28 & $I \cdot 2$ & $I \cdot 3$ \\
\hline 20 & 187 & 173 & 0.62 & 0.71 & $3 \cdot 3$ & $4 \cdot I$ \\
\hline 21 & 255 & 255 & $6 \cdot 18$ & $6 \cdot 32$ & $24 \cdot 2$ & $24 \cdot 8$ \\
\hline 22 & 131 & 156 & 0.78 & $1 \cdot 35$ & 6.0 & $8 \cdot 7$ \\
\hline 23 & 105 & 182 & 0.52 & $I \cdot \mathbf{2 8}$ & $5 \cdot 0$ & $7 \cdot 0$ \\
\hline 24 & 32 & 80 & 0.49 & $I \cdot 05$ & 15.3 & I3.I \\
\hline 25 & 328 & 323 & 3.05 & $2 \cdot 40$ & $9 \cdot 3$ & $7 \cdot 4$ \\
\hline 26 & 163 & 160 & 0.40 & 0.36 & $2 \cdot 5$ & $2 \cdot 3$ \\
\hline 27 & 150 & 301 & 0.40 & 0.52 & $2 \cdot 7$ & $x \cdot 7$ \\
\hline 28 & I68 & 145 & 0.29 & 0.27 & $\mathrm{I} \cdot 7$ & $1 \cdot 9$ \\
\hline 29 & I5O & 204 & 0.32 & 0.36 & $2 \cdot I$ & $1 \cdot 8$ \\
\hline 30 & 116 & 333 & 0.26 & 0.77 & $2 \cdot 2$ & $2 \cdot 3$ \\
\hline 31 & 172 & 158 & $x \cdot 65$ & 0.45 & $9 \cdot 6$ & $2 \cdot 6$ \\
\hline 32 & 298 & 153 & 0.64 & 0.32 & $2 \cdot 1$ & $2 \cdot I$ \\
\hline 33 & 165 & 180 & 0.70 & 0.71 & $4 \cdot 2$ & 3.9 \\
\hline 34 & 94 & 95 & 0.44 & 0.43 & $4 \cdot 7$ & 4.5 \\
\hline 35 & 153 & 107 & 0.36 & 0.24 & $2 \cdot 4$ & $2 \cdot 2$ \\
\hline 36 & I I I & 185 & 0.15 & 0.27 & $I \cdot 4$ & $1 \cdot 5$ \\
\hline 37 & 202 & 190 & 0.26 & 0.36 & $I \cdot 3$ & I.9 \\
\hline $3^{8}$ & 133 & 167 & 0.23 & 0.30 & $I \cdot 7$ & $1 \cdot 8$ \\
\hline 39 & I 77 & 148 & 0.35 & 0.30 & $2 \cdot 0$ & $2 \cdot 0$ \\
\hline 40 & 233 & 306 & $I \cdot 15$ & $2 \cdot 58$ & $4 \cdot 9$ & $8 \cdot 4$ \\
\hline 4I & 270 & 280 & $4 \cdot 30$ & $4 \cdot 18$ & 15.9 & 14.9 \\
\hline 42 & 244 & 300 & $2 \cdot 38$ & $4 \cdot 34$ & $9 \cdot 8$ & $14 \cdot 5$ \\
\hline 43 & 280 & 280 & 0.94 & 0.99 & $3 \cdot 4$ & $3 \cdot 6$ \\
\hline 44 & 196 & 300 & 0.40 & 0.64 & $2 \cdot 0$ & $2 \cdot 1$ \\
\hline 45 & 290 & 196 & 0.94 & 0.55 & $3 \cdot 2$ & $2 \cdot 8$ \\
\hline 46 & 236 & 200 & 0.38 & 0.32 & $x \cdot 6$ & $1 \cdot 6$ \\
\hline 47 & 158 & 218 & 0.42 & 0.46 & $2 \cdot 7$ & $2 \cdot I$ \\
\hline $4^{8}$ & 238 & 200 & 0.49 & 0.46 & $2 \cdot I$ & $2 \cdot 3$ \\
\hline
\end{tabular}

TABLE II (continued)

\begin{tabular}{|c|c|c|c|c|c|c|}
\hline \multirow[t]{2}{*}{$\begin{array}{l}\text { Worker } \\
\text { No. }\end{array}$} & \multicolumn{2}{|c|}{$\begin{array}{c}\text { Creatinine } \\
(\mathrm{mg} . / 100 \mathrm{ml} .)\end{array}$} & \multicolumn{2}{|c|}{$\begin{array}{c}A L A \\
(\mathrm{mg} . / 100 \mathrm{ml} .)\end{array}$} & \multicolumn{2}{|c|}{$\underset{\text { creatinine) }}{A L A}$ (mg./g } \\
\hline & 24 hours & Fresh & 24 hou & Fresh & 24 hour & Gresh \\
\hline $\begin{array}{l}49 \\
50\end{array}$ & $\begin{array}{l}236 \\
188\end{array}$ & $\begin{array}{r}310 \\
66\end{array}$ & $\begin{array}{l}I \cdot 78 \\
0 \cdot 40\end{array}$ & $\begin{array}{l}2 \cdot 49 \\
0 \cdot 20\end{array}$ & $\begin{array}{l}7 \cdot 5 \\
2 \cdot 1\end{array}$ & $\begin{array}{l}8 \cdot 0 \\
3 \cdot 0\end{array}$ \\
\hline $\begin{array}{l}51 \\
52\end{array}$ & $\begin{array}{l}160 \\
162\end{array}$ & $\begin{array}{l}180 \\
120\end{array}$ & $\begin{array}{l}0.55 \\
0.40\end{array}$ & $\begin{array}{l}0.49 \\
0.33\end{array}$ & $\begin{array}{l}3 \cdot 4 \\
2 \cdot 5\end{array}$ & $\begin{array}{l}2 \cdot 7 \\
2 \cdot 8\end{array}$ \\
\hline 53 & 152 & 250 & I.39 & $2 \cdot 40$ & $9 \cdot I$ & $9 \cdot 6$ \\
\hline 54 & I70 & 160 & 0.52 & 0.52 & $3 \cdot 1$ & $3 \cdot 3$ \\
\hline 55 & 216 & 146 & 0.46 & 0.40 & $2 \cdot I$ & $2 \cdot 7$ \\
\hline 56 & I56 & I68 & $1 \cdot 40$ & $I \cdot 60$ & $9 \cdot 0$ & 9.5 \\
\hline 57 & 178 & $2 I 4$ & 0.30 & 0.45 & $I \cdot 7$ & $2 \cdot 1$ \\
\hline 58 & 230 & 260 & 0.89 & 0.91 & $3 \cdot 9$ & 3.5 \\
\hline
\end{tabular}

I. The collection of 24-hour specimens is difficult to control. Some of the specimens presented by the workers as ' 24 -hour specimens' may have been freshly voided urine. In that case it is not surprising that a very close agreement in laboratory values is found when freshly voided urine is compared with spurious 24-hour specimens. If this is so, there seems to be no need to continue to examine 24-hour specimens. The workers in the factory in question have received firm instructions and many of them have been employed for more than Io years, several of them for up to 20 years in the same factory (Cramér and Dahlberg, 1966). If instructions for the collection of 24-hour specimens are not followed in such a factory, it is unlikely that they will ever be followed closely. If sufficient control is gained by the examination of freshly voided specimens, the extra burden of 24-hour collections should be avoided.

2. Strenuous physical work may cause sweating which leads to concentration of the urine and eliminates the effect of urinary dilution by water or other beverages during the daytime. Our study was carried out during three weeks in May, which is generally not a hot month in Sweden. The weather conditions during the collection period were fair, and excessive sweating did not occur. On the other hand, in several departments in the Storage Battery Factory workers are subjected to raised temperatures (lead-smelting, casting, soldering, parts of assembly line), and increased sweating may occur although the work in itself cannot be regarded as heavy. This leads to the voiding of a more concentrated urine than would be the case at normal temperatures. It is difficult to assess the influence of this factor on the results. This source of concentration has also been pointed out by Ellis (I966). As many other 
workers were employed in departments with a normal temperature and with a very effective ventilation (lead ball-grinding, paste-mixing, tubefilling, battery-formation, electrical charging, mechanical workshop) and the results were nevertheless comparable, it appears that the working conditions in themselves did not greatly influence urinary concentrations and/or that the output of creatinine during work showed even greater variations than those of urinary volume.

Concerning the numerical relationship between values for ALA in $\mathrm{mg}$. $/ 100 \mathrm{ml}$. urine and $\mathrm{mg}$. ALA/g. creatinine, it has been pointed out that very constant findings were obtained in 24-hour specimens as well as in fresh specimens, and that, judging from the present material, a factor of $I: 5$ could be used to transform values expressed as $\mathrm{mg}$./ $100 \mathrm{ml}$. to values related to a gram of creatinine. This is at least valid for that range of ALA concentrations where a future upper permissible hygienic border value will be found. This range corresponds to the span between 40 and $80 \mu \mathrm{g}$. lead/100 ml. blood in workers withdrawn from acute exposure for at least one week (Selander, Cramér, and Hallberg, 1966).

The fact that comparable results were obtained with both methods of expressing ALA excretion strongly suggests that the renal concentration of urine, as reflected in elevated values of both ALA and creatinine, plays a minor role compared with the metabolic activities of lead in determining the urinary concentration of ALA.

This study was supported by grants from Försäkringsföretaget Folksam. Thanks are due to Miss Birgitta Börjesson, who performed the ALA analyses, and to the Central Laboratory of Sahlgrenska Sjukhuset where the determinations of creatinine were performed.

\section{REFERENCES}

Bleiler, R. E., and Schedl, H. P. (1962). F. Lab. clin. Med., 59, 945 .

Buchwald, H. (1964). Ann. occup. Hyg., 7, 125. (1965). Ibid., 8, 265.

Cramér, K., Cramér, H., and Selander, S. (1967). Clin. chim. Acta, 15, 331.

—, and Dahlberg, L. (1966). Brit. F. industr. Med., 23, ror. , and Selander, S. (1965). Ibid., 22, 311 .

Doolan, P. D., Alpen, E. L., and Theil, G. B. (1962). Amer. f. Med., 32, 65 .

Ellis, R. W. (1966). Brit. F. industr. Med., 23, 263.

Haeger-Aronsen, B. (1960). Scand. F. clin. Lab. Invest., I2, suppl. 47.

Jaffe. M. (1886). Hoppe-Seylers Z. physiol. Chem., ro, 391. Mauzerall, D., and Granick, S. (1956). F. biol. Chem., 219, 435.

Molyneux, M. K. B. (1964). Brit. F. industr. Med. 21, 203.

Paget, M., Liefooghe, J., Duhamel, M., and Parent, G. (1962). Ann. Biol. clin., 20, 757.

Selander, S., Cramér, K., and Hallberg, L. (1966). Brit. J. industr. Med., 23, 282. 